\title{
Role of exon-16-deleted HER2 in breast carcinomas
}

\author{
F Castiglioni, E Tagliabue, M Campiglio, S M Pupa, A Balsari' and S Ménard
}

\author{
Molecular Targeting Unit, Department of Experimental Oncology, Istituto Nazionale Tumori, Via Venezian 1, 20133 Milan, Italy \\ ${ }^{1}$ Institute of Pathology, University of Milan, Milan, Italy \\ (Requests for offprints should be addressed to S Ménard; Email sylvie.menard@istitutotumori.mi.it)
}

\begin{abstract}
A splice variant of the human gene HER2, lacking exon-16 ( $\triangle \mathrm{HER} 2$ ) which encodes a small extracellular region, has been described. This altered receptor forms disulfide bond-stabilized homodimers. We report here that the $\triangle \mathrm{HER} 2$ splice variant represents about $9 \%$ of the HER2 mRNA obtained from most of the 46 breast carcinoma samples with HER2 expression levels ranging from $3+$ to 0 by HercepTest. Analysis of human cells transfected with $\Delta$ HER2 or wild-type (WT) cDNA revealed no growth of WT cells in nude mice, whereas clones expressing 10-fold less $\triangle \mathrm{HER} 2$ were tumorigenic. Unlike WT transfectants, $\Delta \mathrm{HER} 2$-expressing cells showed low sensitivity to two new therapeutic drugs targeting receptors of the HER family (ZD1839 and Trastuzumab), whereas an inhibitor of the HER2 tyrosine kinase domain (Emodin) blocked activation of both $\triangle H E R 2$ and WT transfectants. Taken together, our findings indicate that the $\triangle H E R 2$ transcript encodes the transforming form of the oncoprotein. It is plausible that malignant transformation arises when a critical threshold of $\triangle H E R 2$ is reached in HER2-overexpressing tumors. Specific inhibitors of HER2 catalytic activity represent a promising approach to therapy of HER2overexpressing tumors.
\end{abstract}

Endocrine-Related Cancer (2006) 13 221-232

\section{Introduction}

Amplification of the HER2 oncogene is one of the genetic abnormalities in breast tissue responsible for the progression from normal breast epithelia to invasive cancer cells. Recent data (Perou et al. 2000, Ménard et al. 2002, Van'T Veer et al. 2002) have shown that HER2-positive breast carcinomas represent a particularly aggressive tumor subset with increased proliferation and metastatic potential. However, HER2 overexpression is relevant to but not sufficient to induce transformation, as clearly established in mice transgenically expressing the rat protooncogene HER2/neu. In these transgenic mice, tumors arose only when the oncoprotein carried mutations, in particular, small deletions in the extracellular domain that promote HER2/neu transforming activity of this protein through formation of intermolecular disulfide bonds (Siegel et al. 1999). Interestingly, an alternative splice form of the human homologous HER2 gene, containing an in-frame deletion in the same region that is mutated in neu protooncogene transgenic mice, has been detected in human breast carcinomas (Kwong \& Hung 1998, Siegel et al. 1999). This splice variant ( $\triangle$ HER2) encodes a receptor lacking exon 16 (according to Ensembl database-ENSE00001121079), which immediately precedes the transmembrane domain containing two cysteine residues. The loss of these cysteine residues might induce a change in the conformation of the HER2 receptor extracellular domain that promotes intermolecular disulfide bonding and, in turn, homodimers capable of transforming cells. Recent studies have revealed that alternative splicing, resulting in deletions within the extracellular domain of growth factor receptors such as Met (Baek et al. 2004), Ron (Collesi et al. 1996) and fibroblast growth factor receptor 2 (FGFR2) (Li et al. 1995, Meyers et al. 1996), provides a unique mechanism for the generation of novel transcripts encoding constitutively activated molecules.

Studies in mammary carcinoma cells have demonstrated that binding of ligands of the epidermal growth factor (EGF) family to their receptors induces formation of homo- and heterodimers of receptors 
belonging to the same family, with a marked preference for HER2 as a dimer partner (Graus-Porta et al. 1997, Tzahar et al. 1997), and that signals induced by HER2-containing heterodimers have the highest biologic activity among the other possible complexes (reviewed in Yarden \& Sliwkowski 2001). Accordingly, a recent phase II trial has shown that ZD1839, a tyrosine kinase inhibitor which specifically blocks the phosphorylation and function of the epidermal growth factor receptor (EGFR), is active in patients with advanced or metastatic breast cancer (Normanno et al. 2003). Encouraging clinical data have also been obtained with the humanized anti-HER2 antibody (Trastuzumab) in treating HER2-overexpressing breast tumors (Slamon et al. 2001, Burstein et al. 2003, Gennari et al. 2004). However, for reasons that remain unclear, not all patients with HER2-positive tumors respond to these new therapies. Thus, a better understanding of the involvement of the HER2 splice variant in conditioning the response to new therapeutic approaches targeting this receptor might provide an avenue to improving response rates in patients with HER2-overexpressing carcinomas.

In the present study, we analyzed expression levels of the HER2 splice variant in human breast carcinomas and examined the role of this variant in HER2-related tumorigenicity and sensitivity to new therapeutic options that target the HER family receptors.

\section{Materials and methods}

\section{Human tumor samples and HER2 expression analysis}

Primary breast carcinoma tissues were collected within 5 min of surgical resection, snap-frozen in liquid nitrogen and stored at $-80{ }^{\circ} \mathrm{C}$. Samples containing at least $50 \%$ tumor cells, as determined by histologic examination, were selected according to overexpression (25 cases) or no overexpression (21 cases) of HER2 protein. Immunohistochemical staining for HER2 protein was performed by the pathology unit of our institute, using the DAKO HercepTest immunocytochemical assay (DAKO, Glostrup, Denmark), according to the manufacturer's instructions, on $4-\mu \mathrm{m}$-thick sections of formalin-fixed, paraffin-embedded material. This staining was scored as follows:

- 0 or $1+$ : no staining or membrane staining in $<10 \%$ of tumor cells or barely perceptible, incomplete membrane staining in $>10 \%$ of the tumor cells

- 2+: weak to moderate complete membrane staining in $>10 \%$ of tumor cells
- 3+: intense complete membrane staining in $>10 \%$ of tumor cells.

On this basis, tumors were classified as 0 (15 cases), $1+$ ( 6 cases $), 2+(5$ cases $)$ and $3+(20$ cases $)$. All patients were enrolled at the National Cancer Institute of Milan in 2001 and underwent breast surgery. Tumor characteristics were as follows: mean tumor size at pathologic examination, $33.7 \mathrm{~mm}$ (range 15-80 mm); positive lymph-node status, $65 \%(76 \%$ and $52 \%$ in HER2-positive and -negative patients respectively); grade III, $52 \%$ (55\% and 50\% in HER2-positive and negative patients respectively).

Total RNA was isolated from each tumor sample with TRIzol Reagent (Invitrogen) according to the manufacturer's instructions. RNA was quantitated spectrophotometrically. Reverse transcription was carried out at $42^{\circ} \mathrm{C}$ for $60 \mathrm{~min}$, using $1 \mu \mathrm{g}$ total RNA, 50 pmol specific primer for HER2 (5'-CAGATGCCCAGAAGGCGGGAG-3'), $0.5 \mathrm{mM}$ deoxynucleotide triphosphate and $25 \mathrm{U}$ MultiScribe reverse transcriptase (Applied Biosystems, Foster City, CA, USA). To confirm the quality of reverse transcription, PCR analysis was performed in a total volume of $50 \mu \mathrm{l}$ using primer pairs of the HER2 receptor $((+)$ primer, 5'-GGCTCAGTGACCTGTTTGG- $3^{\prime}$ and (-) primer, 5'-TGATGAGGATCCCAAAGACC-3') with an expected amplicon length of $312 \mathrm{bp}$ for the wild-type (WT) receptor and $264 \mathrm{bp}$ for the splice variant receptor. After an initial denaturation step at $95^{\circ} \mathrm{C}$ for $5 \mathrm{~min}, 30$ cycles at $95^{\circ} \mathrm{C}$ for $1 \mathrm{~min}, 55^{\circ} \mathrm{C}$ for $30 \mathrm{~s}$ and $72^{\circ} \mathrm{C}$ for $1 \mathrm{~min}$ were carried out followed by a final extension at $72^{\circ} \mathrm{C}$ for $10 \mathrm{~min}$. PCR products were electrophoresed in $8 \%$ polyacrylamide gel, stained with ethidium bromide and visualized under UV lamp.

\section{Real-time PCR}

Primers and TaqMan probes were designed with Primer Express 1.5 software (Applied Biosystems) and purchased from Applied Biosystems. Amplification reactions were performed in a volume of $25 \mu \mathrm{l}$ with $1 \times$ TaqMan Universal PCR Master Mix (Applied Biosystems), $100 \mathrm{nM}$ of each primer and $200 \mathrm{nM}$ probe. The thermal cycling conditions were $95^{\circ} \mathrm{C}$ for $10 \mathrm{~min}, 45$ cycles of $95^{\circ} \mathrm{C}$ for $15 \mathrm{~s}$ and $61^{\circ} \mathrm{C}$ for $30 \mathrm{~s}$. In all experiments, $50 \mathrm{ng}$ cDNA was amplified in singlemeasurement fluorescence, and all data were collected by a 5700 SDS thermal cycler (Applied Biosystems). Each sample was tested in triplicate, and all PCR runs were performed three times. For WT HER2 amplifications, the TaqMan probe and forward primer were located in exon 16, whereas the reverse primer 
annealed in exon 17; for exon 16-deleted HER2 receptor, the probe and reverse primer were located in exon 17, whereas the forward primer encompassed the boundary spanning 15-17 exons.

Real-time PCR probes used were as follows:

- 6-FAM 5'-AAGGGCTGCCCCGCCGA-3' TAMR for WT

- 6-FAM 5'-ACGTCCATCATCTCTGCGGTGG$3^{\prime}$ TAMRA for $\triangle$ HER2.

Real-time PCR forward primers used were as follows:

- 5'-TCCTGTGTGGACCTGGATGA-3' for WT

- 5'-CAACTGCACCCACTCCCC-3' for $\triangle$ HER2.

Real-time PCR reverse primers used were as follows:

- 5'-ACCAGCAGAATGCCAACCA-3' for WT

- 5'-CTTGATGAGGATCCCAAAGACC-3' for $\triangle \mathrm{HER} 2$.

The specificity of primers and probes was verified by assaying each in combination with different concentrations of plasmid vector carrying cloned WT or alternatively spliced HER2 cDNA; fluorescence signal was generated during real-time PCR. The efficiency of probe and primer sets was calculated from the threshold cycles obtained with 10 -fold dilutions (100 ng to $0.1 \mathrm{pg}$ ) of WT or $\triangle \mathrm{HER} 2 \mathrm{cDNA}$ cloned in the pcDNA3 vector. Correlation between the threshold cycles and the input DNA quantities (log units) was used to obtain two calibration curves whose linear regression slopes were used to calculate efficiency by the formula $\mathrm{E}=10^{(-1 / \mathrm{slope})}$ (Pfaffl 2001). For two different breast carcinoma samples (controls), the ratio between the $\triangle$ HER 2 and WT HER2 transcript levels was calculated by the formula $\mathrm{T}_{\Delta \mathrm{HER} 2} / \mathrm{T}_{\mathrm{WT}}=$ $\left(\mathrm{E}_{\mathrm{WT}}\right)^{\mathrm{CtWT}} /\left(\mathrm{E}_{\Delta \mathrm{HER} 2}\right)^{\mathrm{Ct} \Delta \mathrm{HER} 2}$, where $\mathrm{T}$ is the amount of WT or $\triangle$ HER2 mRNA in each sample before amplification, $\mathrm{E}$ is the reaction efficiency and $\mathrm{Ct}$ is the threshold cycle. The WT and $\triangle$ HER 2 threshold cycles of other breast carcinoma samples were normalized to the two controls by the mathematical model described by Pfaffl (2001).

\section{PCR and vectors}

Plasmid pcDNA3/HER2-WT was prepared by excising full-length human HER2 cDNA from the LTR-2/erbB-2 expression vector (kindly provided by Dr P P Di Fiore) (Di Fiore et al. 1987) by XhoI digestion (New England BioLabs, Beverly, MA, USA) and subcloning the fragment into the XhoI site of plasmid pcDNA3 (Invitrogen). The pcDNA3/AHER2 vector was obtained as previously described (Kwong \& Hung 1998).

\section{Cells and treatments}

The SKBr3 human breast carcinoma, HEK-293 embryonic kidney and NIH3T3 murine fibroblast cell lines were provided by ATCC (Rockville, MD, USA). Cells were maintained in RPMI-1640 medium (Sigma) supplemented with $10 \%$ fetal calf serum (FCS), L-glutamine and antibiotics.

Transfections were performed with cells at $80 \%$ confluence in serum-free medium with $10 \mu \mathrm{g}$ DNA, $30 \mu \mathrm{g}$ Lipofectamine reagent and $20 \mu \mathrm{g}$ Plus reagent according to the manufacturer's instructions (Invitrogen). Cells were kept at $37^{\circ} \mathrm{C}$ for $4 \mathrm{~h}$, and, after replacement of serum-free with complete medium, they were maintained for an additional $2 \mathrm{~h}$. Transiently transfected cells were treated with different drugs within $48 \mathrm{~h}$ of transfection. Sensitivity to $25-50 \mu \mathrm{M}$ ZD1839 was evaluated after $72 \mathrm{~h}$ of treatment; the activity of Emodin was used at 20 and $40 \mu \mathrm{M}$ and assayed at $24 \mathrm{~h}$ after treatment. Concentrations of both drugs corresponded to growth inhibition $\mathrm{IC}_{50}(50 \mu \mathrm{M}$ ZD1839 and $40 \mu \mathrm{M}$ Emodin $)$ and $\mathrm{IC}_{30}(25 \mu \mathrm{M}$ ZD1839 and $20 \mu \mathrm{M}$ Emodin) calculated in HEK-293 cells overexpressing WT HER2. Stably transfected cells were selected in the presence of $1 \mathrm{mg} / \mathrm{ml} \mathrm{G} 418$, and individual G418-resistant colonies were picked, expanded and maintained in the presence of G418. Control cells were transfected with pcDNA3 vector (mock). Individual clones of G418-selected cells were tested for $185^{\mathrm{HER} 2}$ surface expression by FACScalibur analysis.

\section{Monoclonal antibodies}

The following monoclonal antibodies $(\mathrm{mAb})$ were used: mouse MGR2 (Tagliabue et al. 1991) and humanized Trastuzumab, directed against the extracellular domain of $\mathrm{p} 185^{\mathrm{HER} 2}$; c-neu $\mathrm{Ab} 3$, directed against the carboxy-terminal peptide of $\mathrm{p} 185^{\mathrm{HER} 2}$ (Oncogene Science, Manhasset, NY, USA); and 4G10, directed against phosphotyrosine (Upstate Biotechnology, Lake Placid, NY, USA).

\section{Western blot analysis}

Transfected cells were solubilized with lysis buffer (50 mM Tris- $\mathrm{HCl}$ (pH 7.4), $150 \mathrm{mM} \mathrm{NaCl}, 1 \%$ Triton X-100, $2 \mathrm{mM}$ Na-orthovanadate, $1 \mathrm{mM}$ phenylmethylsulfonyl-fluoride, $10 \mu \mathrm{g} / \mathrm{ml}$ leupeptin and $10 \mu \mathrm{g} / \mathrm{ml}$ aprotinin), and lysates were centrifuged at $15500 \mathrm{~g}$. for $10 \mathrm{~min}$ at $4{ }^{\circ} \mathrm{C}$. Total cell lysates $(50 \mu \mathrm{g} /$ lane $)$ were 
subjected to $3-10 \%$ gradient SDS-PAGE with a lowconcentration stacking gel (4\%). Proteins were blotted to nitrocellulose membranes (Amersham), nonspecific binding was blocked with Blotto solution (5\% low-fat dry milk in PBS), and membranes were probed with antibodies. Proteins were visualized with peroxidasecoupled secondary antibody by the ECL detection system (Amersham).

\section{Flow cytometric analysis}

Indirect immunofluorescence assay was performed on live cells with MGR2 purified mAb $(10 \mu \mathrm{g} / \mathrm{ml})$ or Trastuzumab $(10 \mu \mathrm{g} / \mathrm{ml})$. Cells were incubated with $100 \mu \mathrm{l}$ antibody for $30 \mathrm{~min}$ at $37^{\circ} \mathrm{C}$, washed twice, and incubated with FITC-labeled goat antimouse $\mathrm{IgG}$ or FITC-labeled goat antihuman IgG (1:100) (Kirkegaard \& Perry Laboratories, Gaithersburg, MD, USA) for $30 \mathrm{~min}$ at $0^{\circ} \mathrm{C}$. After a final wash, cells were suspended in PBS. Fluorescence was evaluated by FACScalibur with CellQuest software (Becton Dickinson, Mountain View, CA, USA).

\section{Apoptosis assay}

Cells grown to $60 \%$ confluency in $10 \mathrm{~mm}^{2}$ dishes were examined by indirect immunofluorescence assay with the annexin V-FITC Kit (Bender MedSystem, Vienna, Austria) according to the manufacturer's protocol.

For qualitative analysis of cytoplasmic DNA fragmentation, adherent and floating cells were harvested, washed once, centrifuged, resuspended in $200 \mu \mathrm{l}$ lysis buffer $(10 \mathrm{mM}$ Tris-HCl $(\mathrm{pH} 8.0), 10 \mathrm{mM}$ EDTA and $0.5 \%$ Triton X-100) and kept on ice for $5 \mathrm{~min}$. After centrifugation at $15500 \mathrm{~g}$, the supernatant was collected and treated overnight at $37^{\circ} \mathrm{C}$ with $100 \mu \mathrm{g} / \mathrm{ml}$ RNase A (Boehringer, Mannheim, Germany) before addition of SDS and proteinase K (Sigma) at $0.5 \%$ and $200 \mu \mathrm{g} / \mathrm{ml}$ respectively. Extracts were incubated at $50^{\circ} \mathrm{C}$ for $2 \mathrm{~h}$, and low-molecular-weight DNA was extracted twice in phenol and once in phenolchloroform. Resuspended DNA was loaded on a 1.5\% ethidium bromide-stained agarose gel.

\section{Proliferation assay}

Transfected NIH3T3 $\left(1 \times 10^{3}\right)$ or HEK-293 $\left(1 \times 10^{4}\right)$ cells were seeded in 96-well plates and maintained in $10 \%$ FCS with the appropriate G418 concentration. After each day of growth, cells were fixed with cold $10 \%$ trichloroacetic acid for $1 \mathrm{~h}$ at $4{ }^{\circ} \mathrm{C}$, washed with PBS and incubated for $30 \mathrm{~min}$ with $0.4 \%$ sulforodamine B (SRB) in $1 \%$ acetic acid $(100 \mu \mathrm{l} /$ well). After three washes in $1 \%$ acetic acid, the dye was dissolved in $10 \mathrm{mM}$ Tris $(\mathrm{pH} \mathrm{10.5)}(100 \mu \mathrm{l} /$ well $)$ and evaluated spectrophotometrically at $550 \mathrm{~nm}$. Growth index was calculated as the ratio of optical density (OD) of a sample after each day of treatment/OD of the sample at the beginning of the experiment.

\section{In vivo cellular tumorigenesis}

Eight-week-old BALB/c athymic mice were purchased from Charles River (Calco, Italy). Care and use of the animals was in accordance with institutional guidelines. Mice were injected subcutaneously in the right flank with $8 \times 10^{5}$ WT- or $\triangle$ HER2-transfected cells, and tumors were calibrated twice weekly. Tumor volume was calculated as $0.5 \times \mathrm{d}_{1}{ }^{2} \times \mathrm{d}_{2}$, where $\mathrm{d}_{1}$ and $\mathrm{d}_{2}$ are the larger and smaller diameters respectively.

\section{Statistics}

Tumor growth was evaluated by Fisher's and chisquare tests. Differences were considered significant at $P<0.05$.

\section{Results}

\section{Expression of alternatively spliced and wild-type HER2 mRNA in human breast carcinomas}

Total RNA obtained from 46 samples of breast carcinoma tissue was retrotranscribed, and this was followed by real-time PCR using two 5'-FAMmodified probes and different primers designed to detect and amplify only WT or splice variant HER2 mRNA. Specificity of the primer pairs was controlled with WT or $\triangle$ HER2 cDNA cloned in the pcDNA3 vector as template, and confirmed by PAGE separation of real-time PCR products, resulting in the respective single band with the expected length. Based on the efficiencies of amplification reactions and threshold cycles of two tumor samples (controls) classified as HercepTest $3+$ and $1+$, the ratio between the expression level of splice variant and WT receptor in controls was calculated as $9 \%$ (see Materials and methods). The ratio between the normalized WT and splice variant expression level was then determined for each tumor sample by the following formula:

$$
\begin{aligned}
\mathrm{R}= & \mathrm{R} 1 / \mathrm{R} 2= \\
& \mathrm{E}_{\text {WTHER2 }} \Delta \mathrm{Ct}\left(\text { control-sample) } / \mathrm{E}_{\triangle \mathrm{HER} 2} \Delta \mathrm{Ct}(\text { control-sample) }\right.
\end{aligned}
$$

A direct correlation between sample R1 and R2 values was found $(r=0.99)$ that revealed in most cases a relative abundance of splice variant mRNA compared with the WT of $9 \%$ (Fig. 1). In eight tumors, the ratio 


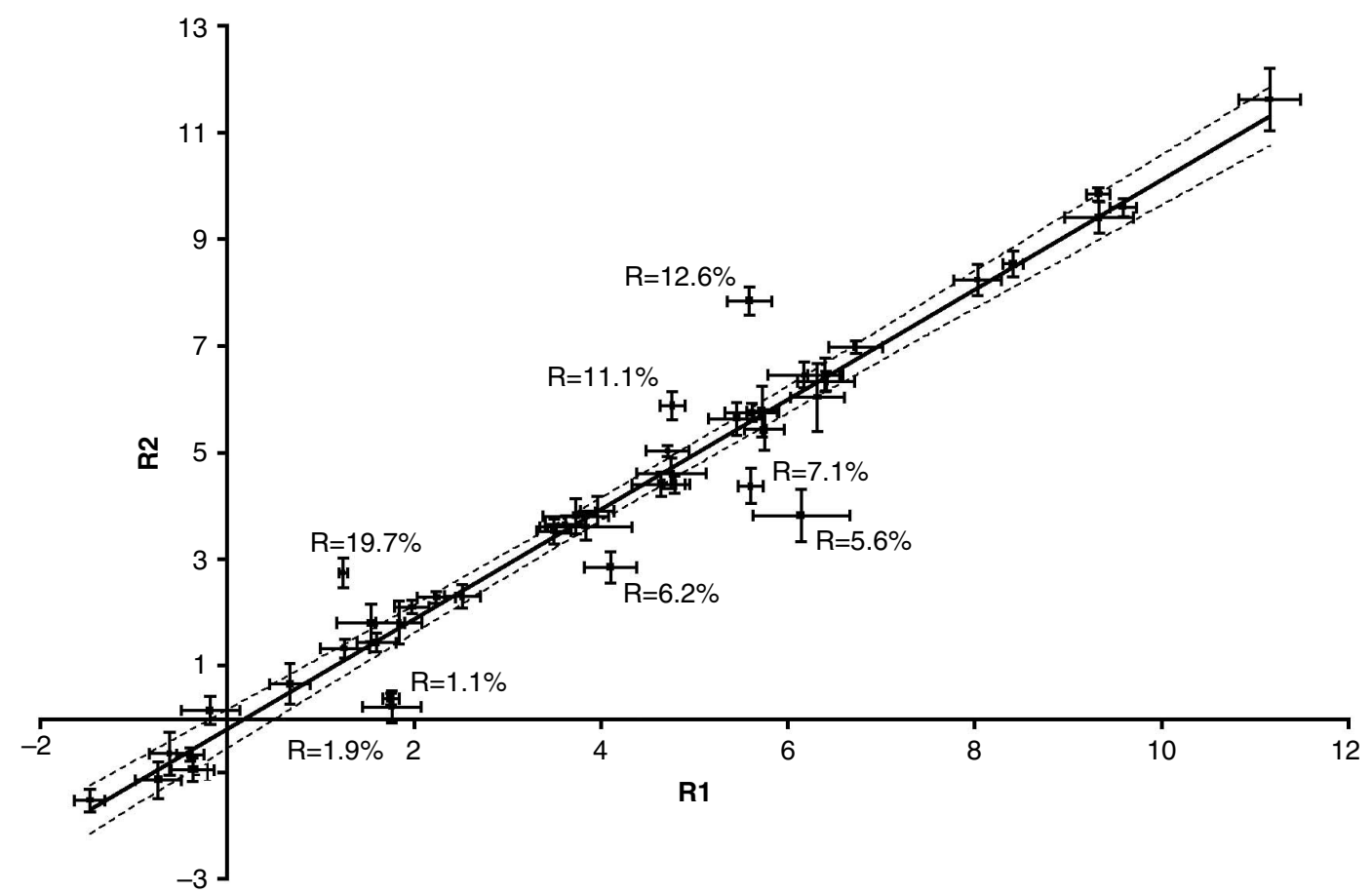

Figure 1 Real-time PCR threshold cycles obtained from cDNA amplification of 46 breast carcinoma samples (R1= $\Delta$ CtWT (control sample) and R2 $=\Delta \mathrm{Ct} \Delta \mathrm{HER} 2$ (control sample)). Values represent the mean of three independent experiments $( \pm$ s.E.M.) for alternative splice and WT amplification. Expression ratio is also shown for cases out of the $95 \%$ confidence interval in the regression line.

of $\triangle \mathrm{HER} 2$ mRNA compared with the WT exceeded the $95 \%$ confidence interval $(8.6-9.9 \%)$, ranging from $19.7 \%$ to $1.1 \%$. Three samples, scored 0 (two cases) and $3+$ (one case) by HercepTest, expressed more than $9 \%$ of $\triangle$ HER 2 , and five samples, scored 0 (two cases) and $3+$ (three cases), expressed less than $9 \%$ of $\triangle$ HER2. While determination of $\triangle$ HER2 ratios in global tumor samples instead of microdissected carcinomas did not exclude the possibility that the splice variant derives from cellular types other than carcinoma, the presence of at least $50 \%$ tumor cells in the samples tested makes it highly unlikely that transcript of nontumor cells was prevalently examined. Indeed, in normal mammary cells, which have never been found to overexpress HER2, the low levels of $\triangle$ HER2 mRNA ( $9 \%$ of the WT) would not affect quantitation of $\triangle$ HER2.

\section{Cellular expression of splice variant HER2}

$\triangle$ HER2 cDNA was obtained from total RNA of the HER2-overexpressing breast carcinoma cell line SKBr3 by recombinant PCR and cloned into the pcDNA3 expression vector (see Materials and methods). To determine whether receptors encoded by the splice variant were activated by the formation of disulfide bond-stabilized dimers, proteins from NIH3T3 cells transfected with WT and $\triangle$ HER 2 cDNA constructs were examined by immunoblot analysis of individual clones obtained after selection in G418 medium and indirect immunofluorescence assay. Elevated levels of disulfide bond-stabilized dimers in each established cell line expressing the HER2 splice variant were detected when soluble extracts were resolved under nonreducing electrophoresis conditions, but not when 2-mercaptoethanol was present (Fig. 2A, lanes 3 and 4). By contrast, NIH3T3 cells expressing WT HER2 revealed monomeric HER2 oncoprotein in both reducing and nonreducing conditions (Fig. 2A, lanes 1 and 2). Moreover, individual $\triangle$ HER 2 clones showed a significantly higher growth capacity both in vitro $(P=0.0004)$ (Fig. $2 \mathrm{~B})$ and in vivo $(P<0.001)$ (Fig. $2 \mathrm{C})$ compared with WT transfectants.

To establish the role of the $\triangle \mathrm{HER} 2$ receptor in transformation, human embryonic kidney cells (HEK293), which have been used as normal human cells to study the oncogenic potential of genes (Graham et al. 1977, Kamei et al. 2003), were transfected with either $\triangle \mathrm{HER} 2$ or WT $\mathrm{cDNA}$ cloned in the pcDNA3 vector. 
A
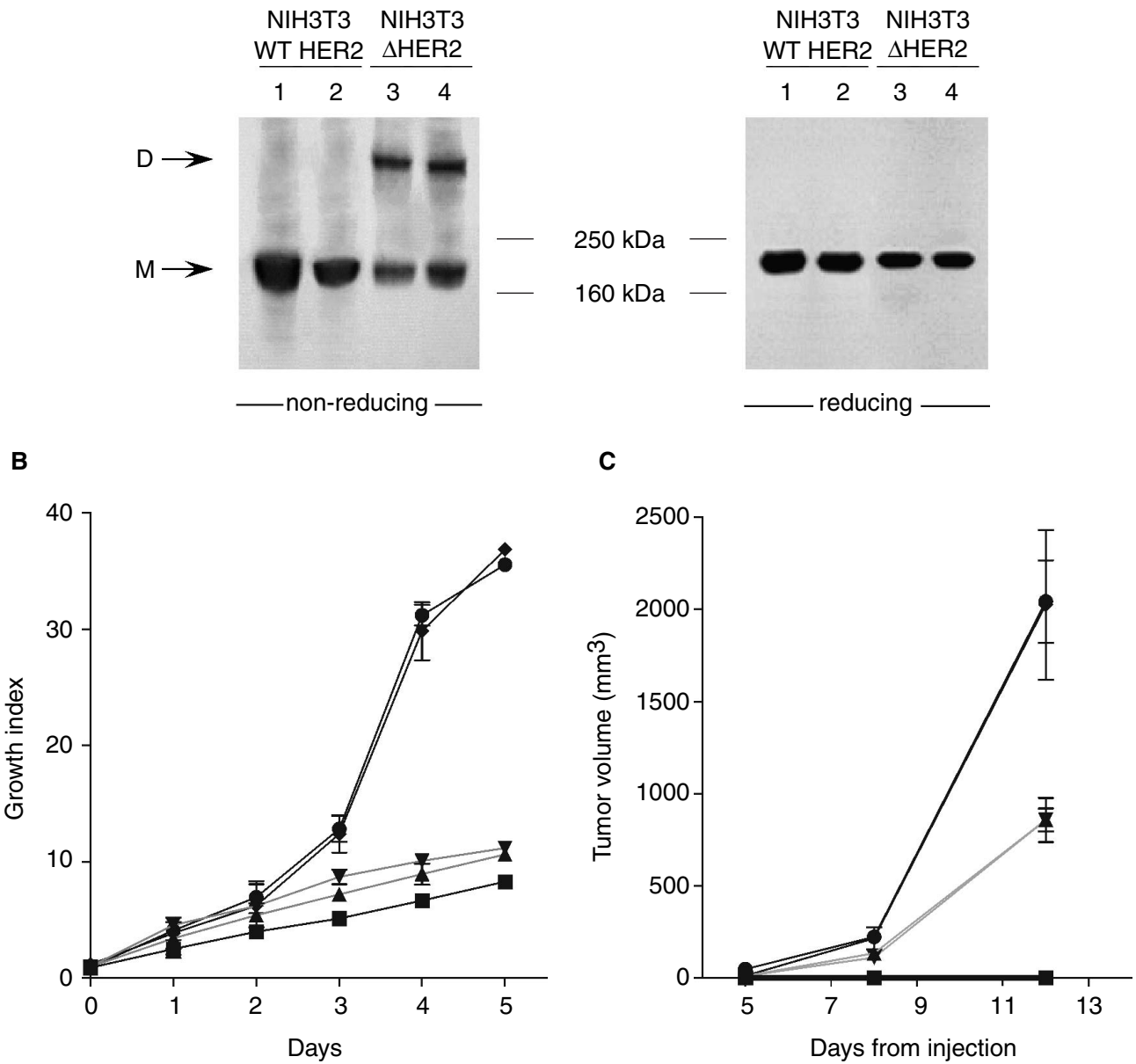

Figure 2 (A) Biochemical analysis of homodimer expression in NIH3T3 transfected clones. Proteins were separated on 3-10\% gradient SDS-PAGE under nonreducing (left) or reducing conditions (right) and probed with monoclonal antibody Ab3 directed against the HER2 receptor. ' $\mathrm{D}$ ' indicates the $\triangle \mathrm{HER} 2$ dimers and 'M' indicates the monomers. (B) In vitro growth of selected NIH3T3 clones overexpressing WT $(\theta, \pi)$ or $\triangle$ HER2 $(\boldsymbol{O}, \mathbf{\Delta})$ or mock $(\boldsymbol{\square})$ NIH3T3. Cells were cultured for 5 days in $96-$-well plates, fixed and stained with SRB. Growth index was calculated as the ratio between OD on a given day and the starting OD. (C) In vivo growth capability of selected WT $(\theta, \pi)$ or $\Delta$ HER $2(\boldsymbol{O}, \boldsymbol{\nabla})$ clones or mock $(\boldsymbol{\square})$ NIH3T3. Tumors in mice injected with $8 \times 10^{5}$ cells were measured twice weekly, and tumor volume was calculated (mean \pm S.D.).

HEK-293 cells have a high transfection rate facilitating biochemical analysis of $\triangle$ HER2 in transient transfectants, unlike human normal breast cell lines which generally present low transfection rates. Immunoblot analysis of cell extracts obtained $48 \mathrm{~h}$ after transfection revealed the presence of HER 2 disulfide dimers in the lysates of splice variant transfectants resolved under nonreducing conditions, but not in the presence of 2-mercaptoethanol (Fig. 3A). Two clones overexpressing the WT HER2 at the same level as in SKBr3, and two clones expressing about 10 -fold less $\triangle$ HER 2 as determined by FACS analysis were selected (Fig. 3B).
The two splice variant clones presented an in vitro growth index comparable to that of the two WT HER2-expressing clones and of the mock-transfected cells (data not shown). These transfectants and two empty, vector-transfected clones were injected in nude mice (six animals/clone). Both $\triangle$ HER2 clones formed tumors with similar growth patterns in $2 / 6$ injected mice (Fig. 3C), whereas cells transfected with WT HER 2 or empty vector did not form tumors $(\triangle H E R 2$ vs WT HER2; $P=0.04$ ). On the other hand, in vitro growth analysis of HEK-293 clones expressing HER2 splice variant at levels comparable with those in 
WT HER2-overexpressing clones (Fig. 4A) revealed a lower growth index in the HER2 splice variantoverexpressing clones than mock or WT-expressing HEK-293 clones (Fig. 4B). Analysis of phosphatidylserine expression in immunofluorescence assays indicated apoptotic death in about $40 \%$ of the cells in the $\triangle$ HER2-overexpressing clones compared with only about $10 \%$ of WT HER2-expressing cells (Fig. 4C). Activation of apoptotic pathways was confirmed by the presence of cytoplasmic DNA fragmentation in the splice variant transfectants (data not shown).

\section{Splice variant sensitivity to new therapies against HER2}

To investigate the responsiveness to new therapeutic tools targeting receptors of the HER family, HER2 activation was analyzed in cells transiently transfected with splice variant or WT HER2 cDNAs and treated with ZD1839, a specific inhibitor of the EGFR tyrosine-kinase domain. Western blot analysis revealed an inhibition of phosphorylation of monomeric HER2 receptor expressed by the splice variant (Fig. 5A), indicating the expected involvement of monomeric HER2 receptors in EGFR-driven heterodimers. By contrast, ZD1839 at the same concentrations did not detectably inhibit phosphorylation of the high-molecular-weight species corresponding to disulfide-bond dimeric HER2 present only in splice variant-transfected cells (Fig. 5A). In transiently transfected HEK-293 cells treated with Emodin, a tyrosine-kinase inhibitor affecting the HER2 catalytic domain (Jayasuriya et al. 1992, Zhang et al. 1999), neither HER2 monomeric nor disulfide-bond HER2 was found to be phosphorylated (Fig. 5B), indicating that the constitutive phosphorylation of disulfide-bond HER2 homodimers is sensitive to this tyrosine kinase inhibitor. Complete inhibition of HER2 monomeric phosphorylation was observed at an Emodin concentration that inhibits proliferation by only $30 \%$, suggesting that other proliferation pathways were active. The humanized antibody Trastuzumab recognizes a conformational epitope in the juxtamembrane region of HER2, which might be altered in the $\triangle$ HER2 variant. Indirect immunofluorescence assay of Trastuzumab binding with transfected HEK-293 cells revealed a mean fluorescence intensity in WT HER2-expressing clones similar to that obtained with MGR2, an anti-HER2 mAb that does not cross-react with Trastuzumab. By contrast, the splice variant HER2-expressing cells were completely negative with Trastuzumab but positive with MGR2 antibody. However, human antibody reactivity with the splice variant-expressing cells was restored when cells were cultured in the presence of increasing concentrations of 2-mercaptoethanol (Table 1).

\section{Discussion}

The present study demonstrates that the HER2 splice variant lacking exon 16 is expressed in breast carcinoma samples as a proportion (about 9\%) of the WT amount of encoded HER2. Moreover, the splice variant, at 10 -fold lower concentrations than the WT receptor-overexpressing clones, induces transformation of human cells, suggesting that transformation associated with HER2 overexpression might reflect the increase in absolute levels of the splice variant to a critical threshold for constitutive activation of HER2. Consistent with this assumption, the formation of tumors in mice transgenically overexpressing the rat neu protooncogene has been associated with mutations of the transgene, including small deletions in the extracellular domain that promote formation of intermolecular disulfide bonds (Slamon et al. 1989, Lemoine et al. 1990, Siegel et al. 1999).

Although our analysis of the HER2 splice variant used more sensitive and quantitative methods than those in the previous study by Siegel et al. (1999), we also found that $\triangle$ HER2 mRNA represents about $9 \%$ of the WT HER 2 transcript in breast carcinomas, and that consequently the absolute levels of the spliced transcript are higher in HER2-overexpressing tumor samples. The consistent direct linear correlation between the abundance of the two HER2 transcript forms indicates the efficiency of splicing machinery even in breast tumors with HER2 gene amplification. Indeed, tumors classified $3+$ presented the same splice variant level found in those scored $2+, 1+$ or 0 by HercepTest. Furthermore, eight cases in which the relationship between the two HER2 forms was found at the $95 \%$ confidence interval, the three samples (one case classified as $3+$ and two cases as 0 ) expressing more than $9 \%$ of $\triangle$ HER 2 and five samples (three cases classified as $3+$ and five cases classified 0 ) expressing less suggested that, in some breast tumors, the regulation of basal splicing machinery might be disturbed.

Consistent with the enhanced focus-forming ability in vitro described for murine fibroblasts transfected with cDNA encoding the alternative spliced receptor (Siegel et al. 1999), we found that expression of the $\triangle$ HER2 receptor in NIH3T3 fibroblast induced transformation, providing a higher proliferation signal than that given by the WT receptor. This enhanced 
F Castiglioni et al.: Exon-16-deleted HER2

A

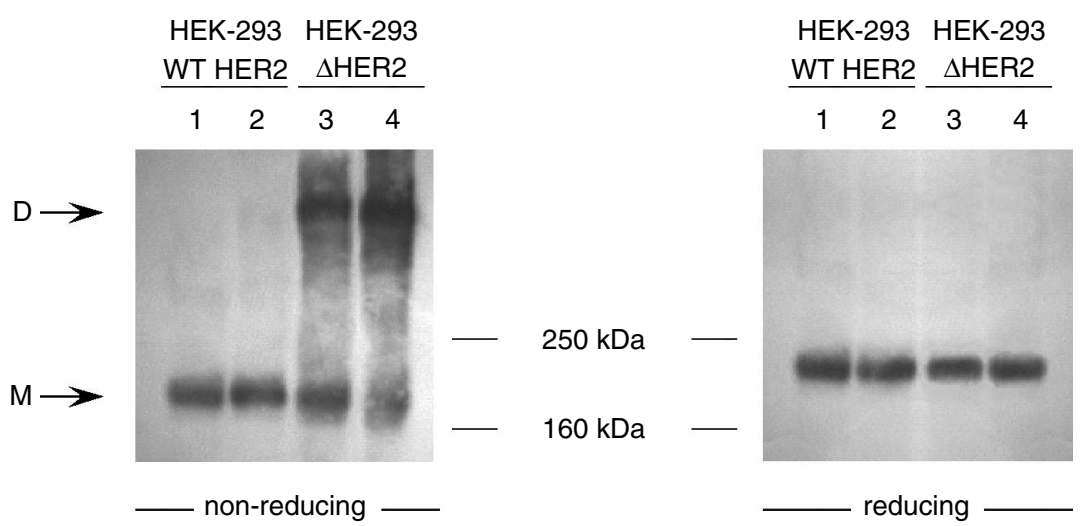

B

HEK-293/WT HER2

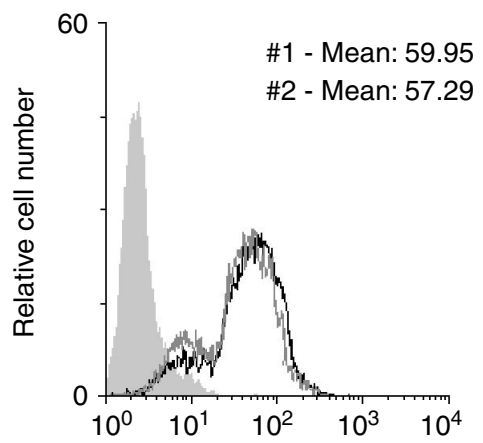

HEK-293/AHER2

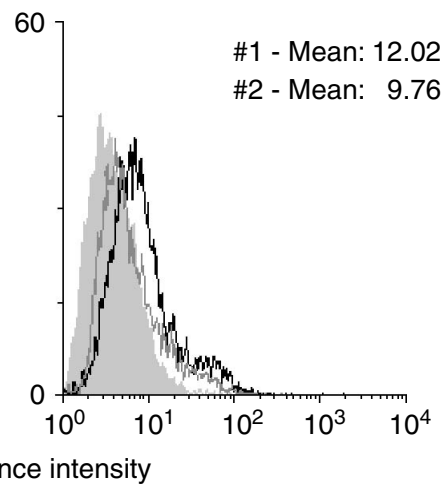

C

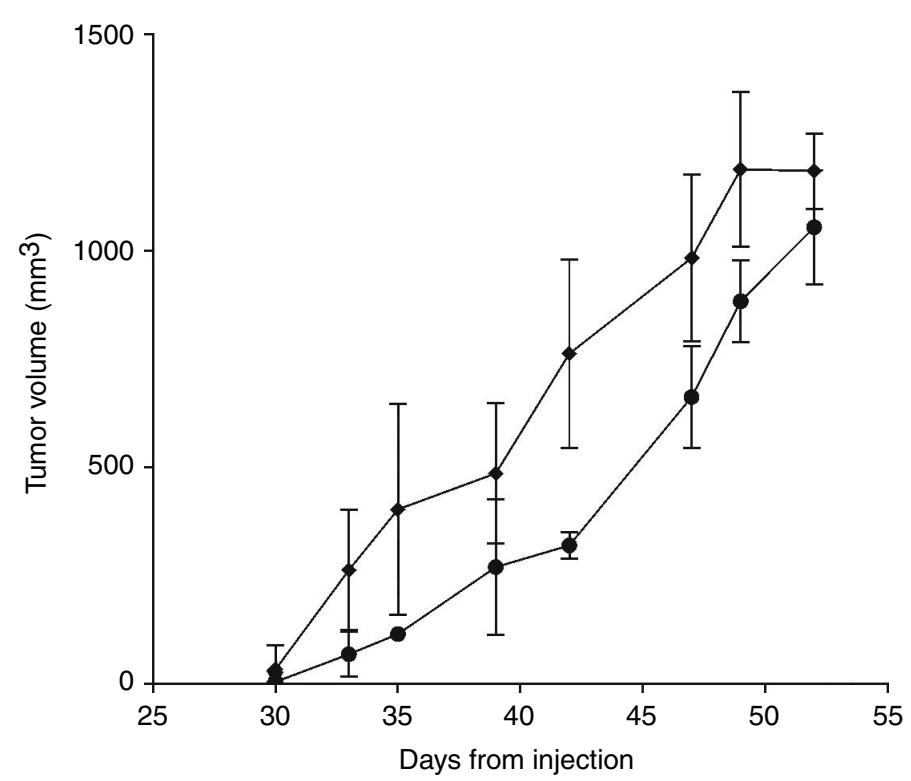

Figure 3 (A) Biochemical analysis of HEK-293 cells at $48 \mathrm{~h}$ from transfection with WT or $\triangle \mathrm{HER} 2 \mathrm{cDNA}$. Proteins were separated on $3-10 \%$ gradient SDS-PAGE under nonreducing (left) or reducing conditions (right) and probed with monoclonal antibody 


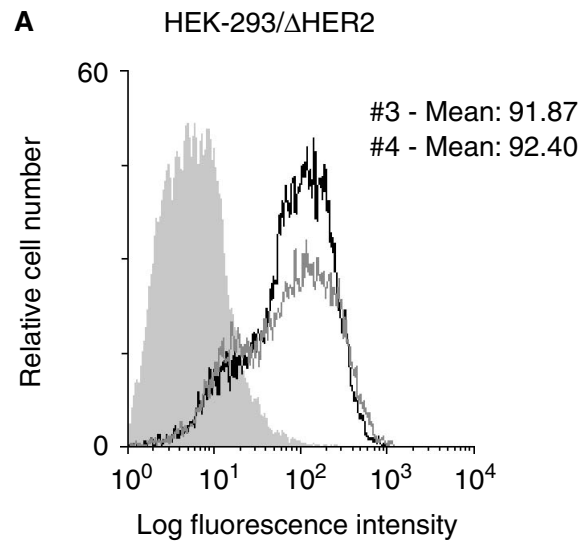

C

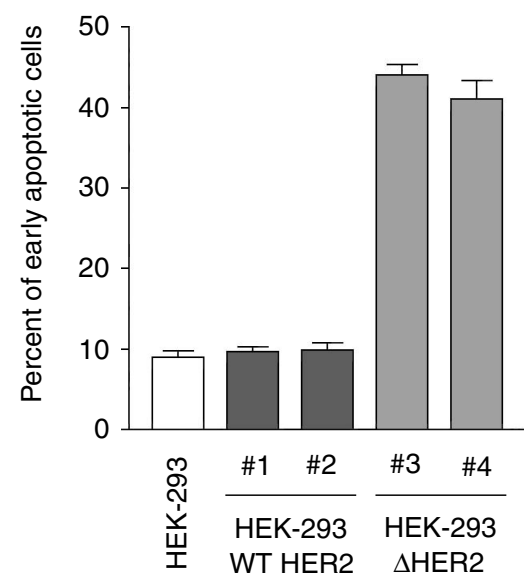

growth signaling can be attributed to disulfide bondstabilized homodimers, as detected under nonreducing conditions in soluble extracts of spliced HER2expressing NIH3T3 cells. Indeed, growth factor receptors that are homodimerized through disulfide bonds are constitutively phosphorylated (Rubin \& Yarden 2001), providing a crucial step in cell growth signaling. Furthermore, it is possible that clustering of EGFR on the plasma membrane of NIH3T3 human fibroblasts driven by activated $\triangle \mathrm{HER} 2$ homodimers contributes to the enhanced oncogenicity of altered HER2 receptors even if none of the selected clones

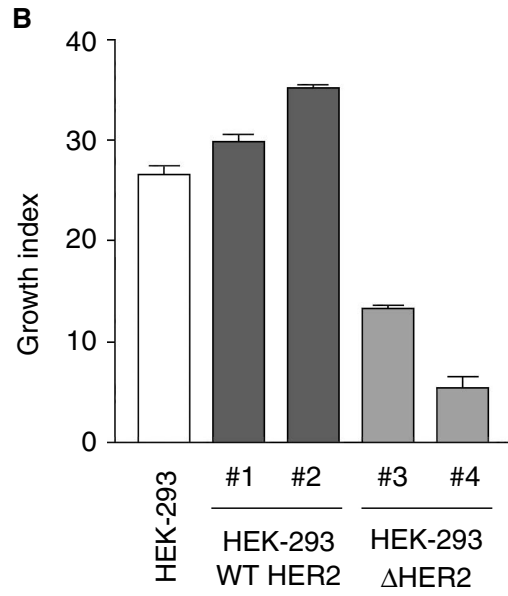

Figure 4 (A) Expression level of HER2 receptor in selected HEK-293 clones evaluated by indirect immunofluorescence assay using MGR2 antibody. The gray area indicates the background value; the empty areas define the fluorescence of clone no. 3 (black line) and clone no. 4 (gray line) expressing $\triangle \mathrm{HER} 2$. Mean fluorescence intensity is indicated. (B) In vitro growth of HEK-293 selected clones. Cells were cultured in monolayer for 5 days and stained with SRB. Growth index was calculated as the ratio between the day-5 OD and the starting OD. (C) Percentage of early apoptosis in HEK-293 selected clones quantified by annexin V/propidium FACS analysis.

exibited significant endogenous EGFR expression levels (data not shown).

Note, however, that in human HEK-293 cells, which reportedly have only moderate sensitivity to transformation (Cheng et al. 2002, Graham et al. 1977), $\triangle$ HER2 was sufficient by itself to initiate tumorigenesis, whereas WT HER2 did not induce cellular transformation. One explanation for these observations is that disulfide bond-homodimerized HER2 does not require the cooperation of other gene alterations to transform human cells. Furthermore, HEK-293 cells expressing high levels of $\triangle$ HER2

Ab3 directed against the HER2 receptor. ' $D$ ' indicates $\triangle H E R 2$ dimers while ' $M$ ' indicates monomers. (B) Indirect immunofluorescence analysis of splice variant or WT HER2 expression levels in selected HEK-293 clones. The gray areas indicate the background values; the empty areas define the fluorescence of clone no. 1 (black line) and clone no. 2 (gray line) expressing HER2. Mean fluorescence intensity is indicated. (C) In vivo growth capability of $\triangle \mathrm{HER} 2$ transfected HEK-293 cells. Tumors of mice injected with $8 \times 10^{5}$ cells were measured twice weekly, and tumor volume was calculated (mean \pm S.D.). 
A

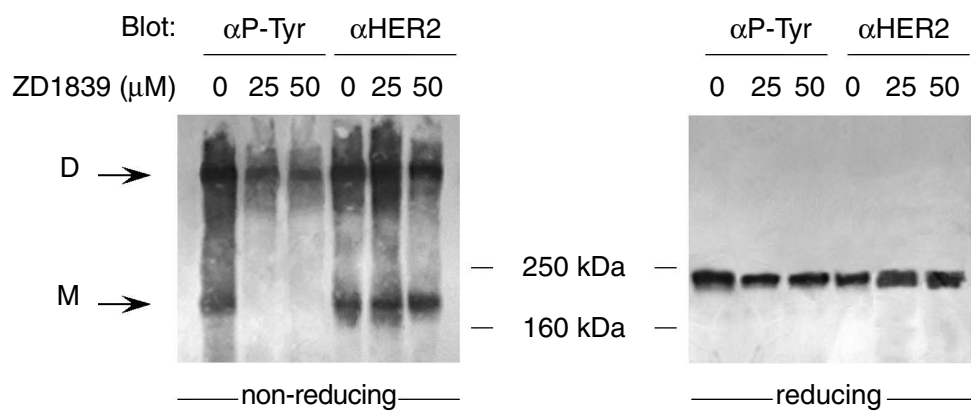

B

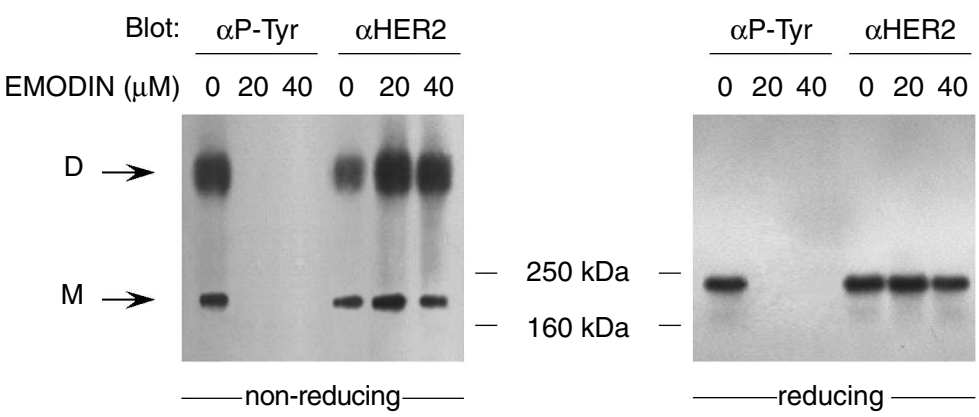

Figure 5 Analysis of HER2 activation in HEK-293 cells transfected with $\triangle$ HER2 cDNA and treated with (A) ZD1839 at three different concentrations $(0,25$ or $50 \mu \mathrm{M})$ or $(B)$ Emodin $(0,20$ or $40 \mu \mathrm{M})$. Total lysates were separated on 3-10\% gradient SDSPAGE under nonreducing (left) or reducing conditions (right). Filters were probed with monoclonal antibody Ab3 ( $\alpha \mathrm{HER} 2)$ or antiphosphotyrosine ( $\alpha$ P-Tyr). 'D' indicates $\triangle$ HER2 dimers while 'M' marks the position of monomers.

Table 1 MGR2 and Trastuzumab reactivity on $\triangle \mathrm{HER} 2$ expressing HEK-293 clones cultured in the presence of 2-mercaptoethanol

\begin{tabular}{llc}
\hline \multirow{2}{*}{$\begin{array}{l}\text { Concentration of } \\
\text { 2-mercaptoethanol }\end{array}$} & \multicolumn{2}{c}{ Mean fluorescence intensity } \\
\cline { 2 - 3 } & MGR2 & Trastuzumab \\
\hline $0 \mu \mathrm{M}$ & 35.9 & 8.4 \\
$25 \mu \mathrm{M}$ & 32.7 & 8.1 \\
$50 \mu \mathrm{M}$ & 33.6 & 20.6 \\
$75 \mu \mathrm{M}$ & 35.8 & 30.5 \\
\hline
\end{tabular}

showed activation of apoptotic pathways, as indicated by the presence of phosphatidylserine outside the cell membrane and by the presence of fragmented cytoplasmic DNA. These findings are consistent with previous evidence showing that normal cells undergo apoptosis upon a highly aberrant cell growth signal (Hognason et al. 2001, Lehto 2001) such as that provided when high levels of constitutively activated $\triangle$ HER2 receptor are expressed. In agreement with this evidence, our findings indicate that alternatively spliced HER 2 never exceeded $20 \%$ of the WT receptor expressed.

Not all molecules encoded by alternatively spliced HER2 mRNA are dimerized in transfected cells, suggesting that disulfide bond stabilization also depends on the redox conditions of the tumor microenvironment. Thus, the proliferation signal derived from dimerized HER2 receptor may change as a function of cellular metabolism as well as the vascular network present around tumor cells.

Importantly, the $\triangle \mathrm{HER} 2$ receptor was found to be resistant to two new breast cancer therapeutic approaches targeting receptors of the HER family, that is, the HER1 tyrosine kinase inhibitor ZD1839 and the humanized anti-HER2 mAb Trastuzumab, but its activation was completely blocked by the HER2 tyrosine kinase inhibitor Emodin. Clinical data showing that not all patients with HER2-positive tumors respond to new HER2-targeted therapies might reflect, in part, the inefficient targeting of the splice variant receptor, particularly, the disulfide-bonded HER2 dimers, by these drugs. Indeed, tyrosine phosphorylation of spliced HER2 in the disulfide bond-stabilized 
dimer form is resistant to treatment with a HER1 tyrosine kinase inhibitor, whereas phosphorylation of the same molecule in monomeric form is completely inhibited, indicating that only the splice variant monomers, and not the homodimers, depend on HER1 activation for phosphorylation. Trastuzumab, which binds to the juxtamembrane region of HER2, also demonstrated a lower reactivity with splice variant-transfected HEK-293 cells, reflecting a lack of reactivity with disulfide-bond HER2 homodimers, since culture of these transfectants in the presence of a reducing agent increased the number of Trastuzumab-positive cells. These results also point to the need for a better understanding of the relevance of redox conditions in the tumor microenvironment to activation of growth factor receptors such as HER2 and, consequently, to antitumor activity of anti-HER2 reagents.

Taken together, our findings suggest the potential role of a constitutively activated $\triangle$ HER2 splice variant in breast carcinomas, as well as the need for therapeutic approaches that target this variant.

\section{Acknowledgements}

This study was supported by Associazione Italiana Ricerca sul Cancro, Milan, Italy. Fabio Castiglioni was supported by a fellowship from FIRC. We thank Mrs Piera Aiello and Mrs Cristina Ghirelli for excellent technical assistance. The authors declare that there is no conflict of interest that would prejudice the impartiality of this scientific work.

\section{References}

Baek CM, Jeon SH, Jang JJ, Lee BS \& Lee JH 2004 Transforming variant of Met receptor confers serum independence and anti-apoptotic property and could be involved in the mouse thymic lymphomagenesis. Experimental Molecular Medicine 36 283-291.

Burstein HJ, Harris LN, Gelman R, Lester SC, Nunes RA, Kaelin CM, Parker LM, Ellisen LW, Kuter I, Gadd MA, Christian RL, Kennedy PR, Borges VF, Bunnell CA, Younger J, Smith BL \& Winer EP 2003 Preoperative therapy with trastuzumab and paclitaxel followed by sequential adjuvant doxorubicin/cyclophosphamide for HER2 overexpressing stage II or III breast cancer: a pilot study. Journal of Clinical Oncology 21 46-53.

Cheng JD, Dunbrack RL Jr, Valianou M, Rogatko A, Alpaugh RK \& Weiner LM 2002 Promotion of tumor growth by murine fibroblast activation protein, a serine protease, in an animal model. Cancer Research 62 $4767-4772$.
Collesi C, Santoro MM, Gaudino G \& Comoglio PM 1996 A splicing variant of the RON transcript induces constitutive tyrosine kinase activity and an invasive phenotype. Molecular and Cellular Biology 16 5518-5526.

Di Fiore PP, Pierce JH, Kraus MH, Segatto O, King CR \& Aaronson SA 1987 erbB-2 is a potent oncogene when overexpressed in NIH/3T3 cells. Science 237 178-182.

Gennari R, Ménard S, Fagnoni F, Ponchio L, Scelsi M, Tagliabue E, Castiglioni F, Villani L, Magalotti C, Gibelli N, Oliviero B, Ballardini B, Da Prada G, Zambelli A \& Costa A 2004 Pilot study of the mechanism of action of preoperative trastuzumab in patients with primary operable breast tumors overexpressing HER2. Clinical Cancer Research 10 5650-5655.

Graham FL, Smiley J, Russell WC \& Nairn R 1977 Characteristics of a human cell line transformed by DNA from human adenovirus type 5. Journal of General Virology 36 59-74.

Graus-Porta D, Beerli RR, Daly JM \& Hynes NE 1997 ErbB-2, the preferred heterodimerization partner of all ErbB receptor, is a mediator of lateral signaling. EMBO Journal 16 1647-1655.

Hognason T, Chatterjee S, Vartanian T, Ratan RR, Ernewein KM \& Habib AA 2001 Epidermal growth factor receptor induced apoptosis: potentiation by inhibition of Ras signaling. FEBS Letter 491 9-15.

Jayasuriya H, Koonchanok NM, Geahlen RL, McLaughlin JL \& Chang CJ 1992 Emodin, a protein tyrosine kinase inhibitor from Polygonum cuspidatum. Journal of Natural Products 55 696-698.

Kamei D, Murakami M, Nakatani Y, Ishikawa Y, Ishii T \& Kudo I 2003 Potential role of microsomal prostaglandin E synthase-1 in tumorigenesis. Journal of Biological Chemistry 278 19396-19405.

Kwong KY \& Hung MC 1998 A novel splice variant of HER2 with increased transformation activity. Molecular Carcinogenesis 23 62-68.

Lehto VP 2001 EGF receptor: which way to go? FEBS Letters 491 1-3.

Lemoine NR, Staddon S, Dickson C, Barnes DM \& Gullick WJ 1990 Absence of activating transmembrane mutations in the c-erbB-2 proto-oncogene in human breast cancer. Oncogene 5 237-239.

Li X, Park WJ, Pyeritz RE \& Jabs EW 1995 Effect on splicing of a silent FGFR2 mutation in Crouzon syndrome. Nature Genetics 9 232-233.

Ménard S, Balsari A, Casalini P, Tagliabue E, Campiglio M, Bufalino R \& Cascinelli N 2002 HER2-positive breast carcinomas as a particular subset with peculiar clinical behaviors. Clinical Cancer Research 8 520-525.

Meyers GA, Day D, Goldberg R, Daentl DL, Przylepa KA, Abrams LJ, Graham JM Jr, Feingold M, Moeschler JB, Rawnsley E, Scott AF \& Jabs EW 1996 FGFR2 exon IIIa and IIIc mutations in Crouzon, Jackson-Weiss, and Pfeiffer syndromes: evidence for missense changes, insertions, and a deletion due to alternative RNA splicing. American Journal of Human Genetics 58 491-498. 
Normanno N, Maiello MR \& De Luca A 2003 Epidermal growth factor receptor tyrosine kinase inhibitors (EGFR-TKIs): simple drugs with a complex mechanism of action? Journal of Cell Physiology 194 13-19.

Perou CM, Sorlie T, Eisen MB, van de Rijn M, Jeffrey SS, Rees CA, Pollack JR, Ross DT, Johnsen H, Akslen LA, Fluge O, Pergamenschikov A, Williams C, Zhu SX, Lonning PE, Borresen-Dale AL, Brown PO \& Botstein D 2000 Molecular portraits of human breast tumours. Nature 406 747-752.

Pfaffl MW 2001 A new mathematical model for relative quantification in real-time RT-PCR. Nucleic Acids Research 29 e45.

Rubin I \& Yarden Y 2001 The basic biology of HER2. Annals of Oncology 12 S3-S8.

Siegel PM, Ryan ED, Cardiff RD \& Muller WJ 1999 Elevated expression of activated forms of Neu/ErbB-2 and Erb-3 are involved in the induction of mammary tumors in transgenic mice: implications for human breast cancer. EMBO Journal 18 2149-2164.

Slamon DJ, Godolphin W, Jones LA, Holt JA, Wong SC, Keith DE, Levin WJ, Stuart SG, Udove J, Ullrich A \& Press MF 1989 Studies of the HER-2/neu protooncogene in human breast and ovarian cancer. Science 244 707-712.

Slamon DJ, Leyland-Jones B, Shak S, Fuchs H, Paton V, Bajamonde A, Fleming T, Eiermann W, Wolter J, Pegram M, Baselga J \& Norton L 2001 Use of chemotherapy plus a monoclonal antibody against
HER2 for metastatic breast cancer that overexpresses HER2. New England Journal of Medicine 344 783-792.

Tagliabue E, Centis F, Campiglio M, Mastroianni A, Martignone S, Pellegrini R, Casalini P, Lanzi C, Ménard S \& Colnaghi MI 1991 Selection of monoclonal antibodies which induce internalization and phosphorylation of $\mathrm{p} 185^{\mathrm{HER} 2}$ and growth inhibition of cells with HER2/neu gene amplification. International Journal of Cancer 47 933-937.

Tzahar E, Pinkas-Kramarski R, Moyer JD, Kapper LN, Alroy I, Levkowitz G, Shelly M, Henis S, Eisenstein M, Ratzkin BJ, Sela M, Andrews GC \& Yarden Y 1997 Bivalence of EGF-like ligands drives the ErbB signaling network. EMBO Journal 16 4938-4950.

Van'T Veer LJ, Dai H, Van de Vijver MJ, He YD, Hart AA, Mao M, Peterse HL, van der Kooy K, Marton MJ, Witteveen AT, Schreiber GJ, Kerkhoven RM, Roberts C, Linsley PS, Bernards R \& Friend SH 2002 Gene expression profiling predicts clinical outcome of breast cancer. Nature 415 530-536.

Yarden Y \& Sliwkowski MX 2001 Untangling the ErbB signalling network. Nature Reviews in Molecular and Cellular Biology 2 127-137.

Zhang L, Lau YK, Xia W, Hortobagyi GN \& Hunh MC 1999 Tyrosine kinase inhibitor emodin suppresses growth of HER2/neu-overexpressing breast cancer cells in athymic mice and sensitizes these cells to the inhibitory effect of paclitaxel. Clinical Cancer Research 5 343-353. 